\title{
A Comparative Analysis of the Dynamics of Engagement in Profit and Non Profit Organisations in India
}

\author{
Shweta Sharma ${ }^{1,}$ Dr. Sanjeevni Gangwani ${ }^{2}$ \\ ${ }^{I}$ Research Scholar, Devi Ahilya Vishwavidyalaya, Indore, (MP). \\ ${ }^{2}$ Professor, Medi Caps University, Indore, (MP).
}

\begin{abstract}
Purpose: This study has been done with special reference to comparing the impact of engagement drivers in non profit and profit service industries in India. Non profit and profit telecom, banking and insurance companies are selected from different cities in India. For measuring employee engagement 59 statements placed under twelve heads were taken as dependent variables whereas non profit and profit organisations were taken as independent variables.

Design/methodology/approach- The study is based on primary data collected from 480 respondents in which 242 are from non profit and 238 from profit telecom, banking and insurance sectors located in India. With the help of a self designed structured questionnaire data was collected on a number of parameters relating to employee engagement and analyzed the data using different tools in SPSS 16 version and interpretations were drawn.

Findings - As different sectors have different work environment and different management styles in the same manner there is a difference in the engagement in non profit and profit organisation, in different sectors some engagement drivers are stronger whereas in other sector the variables which were weak in the previous sector have strong impact in the other. Employee Engagement was found to be better in non profit organisations as compared to profit.

Research limitations/implications - The study is conducted in non profit and profit service sector only. Other service sectors can also be included and the sample size can be increased to get more accurate and genuine results.

Practical implications - Profit organisation emphasises more on employee engagement activities as compared to non profit organisation still engagement is found to be high in non profit sector raising an alarm for the private organisations to emphasize on the areas like security in the job and compensations where they lag from public sector.

Originality/value -In the previous researches the comparison of dynamics of engagement was studied in any one type of industry may be only in insurance, banking or in manufacturing non profit and profit organisation. Very rare researches have been done with combining two or three service industries.
\end{abstract}

Keywords: Engagement, Psychological contract, non profit organisation, profit organisation, dynamics.

\section{INTRODUCTION}

With the emergence of multinational organisations and multigenerational workforce, the study of employee engagement at international level has become alarmingly significant as with the culture of outsourcing and privatisation the competition has become so neck to neck that only the fittest can survive. Employee engagement is the level of attachment and commitment an employee has toward its organisation. The question here arises is that whether or not the same engagement techniques work for employees from different sectors, different types of organisations with different cultures and economies? The research findings of the study conducted by ISR's (2004) strongly indicated that at global level four issues should be taken care of while managing engagement:

The first was Career development focussing on proving opportunities to the employees so that they can develop their aptitude, learn new skills, acquire new knowledge and realise their potential. The main crux behind this is that when organisations invest in their workforce in this way, their people invest in them. The second was Empowerment, nowadays employees want their presence to be noticed and the autonomy to take their decisions and participate in decision making. The research also identified leadership as good leaders create a challenging and transparent work culture where the employees do not have the fear rather they are free to express their views and can exercise their initiatives. The other issue was Image (which refers to the company's image to customers and the employees) that is the perception about the company. Image plays a very vital role 
in making an employee engaged towards an organisation so that the employee can make efforts to move the organisation forward. Different sectors have different merits and demerits, there are some attributes like life time security and compensation \& benefit schemes in government sector that keeps an employee engaged whereas motivation and enhancement \& learning is very strong in profit organisations and is very much responsible for engagement of the workforce. By focussing on the effecting attributes the problem of engagement can be solved to a large extent.

\section{REVIEW OF LITERATURE:}

Bhargavi V.R ( 2015) in her literature review found that the following variables: Work Environment, Organization Culture, Leadership style, Job satisfaction and involvement, Resource support, Compensation and Benefits, Co-employees support, Senior Management, Company Human Resource Policies and procedures, Quality of work life are identified as the indicators of employee engagement.

Aon Hewitt (2013) in his report revealed that the engagement is a psychological and behavioural outcome resulting in better employee performance. He categorised work experience into six areas that is the work people do, the people they work with, opportunities, total rewards, company practices and general quality of life. These drivers proved to be helpful in understanding the requirements of their employees and focus on the specific areas of improvement to get better the business results.

Federal Employee Viewpoint Survey (2014) revealed that engagement among the nation's largest employer has declined. Also, the 2014 Best Places to Work in the Federal Government rankings by the Partnership for Non profit Service showed a decline in federal employee job satisfaction for the fourth year in a row. And, while there are no comparable statistics for state and local government, it is likely that the needle of engagement is moving in the wrong direction in the non profit organisations

Hughes (2012: 228) in his study in non profit organisation concluded that “...staff members made an implicit trade-off between, on the one hand, job security and generous retirement benefits, and, on the other, slow progress and relatively low pay".

Rashid (2011) found in his study that there is a significant relationship between employee engagement and decision-making, performance and reward system.

Ram Padmakumar \& Prabhakar Gantasala V. (2011) revealed in his studies that by using a matrix of predictors of engagement (organizational process, information, reward/recognition, values, management, role challenge, work/life balance, work environment and products / services), HR can assist the organization to handle engagement effectively and ultimately foster motivation, productivity and retention. Whether the people are productive and stay with the organization or quit or perhaps join the competitors depends on the level of engagement and the extent to which employees are associated to the organizational strategy and goal cultivate high levels of engagement in the organisation.

Sardar et al. (2011) indicates that training helps in improving service inaccuracy and it can at once effect service performance and employee engagement as employees who enhance their skills through training are more likely to engage entirely in their work, because they derive more achievement from mastering new tasks resulting into engagement.

Mohpatra and Sharma. (2010) in a study of executives of a non profit organisation organization found that there is a positive and significant relationship between work ethic and employee engagement. They also listed different predictors of employee engagement and found that objectivity, pay and job content are related to organization engagement. Some of the critical predictors derived from the study, were compensation and benefits, performance management, job content and learning and development.

Halbesleben. Gibbons. J. (2006) focussed on employee engagement drivers and found that broadly there are eight important drivers of employee engagement and the drivers are: Trust and Integrity, Nature of the job Career Growth Opportunities, Pride about the company, Co-workers/Team members, Line-of-sight between Individual performance and company performance, Employee Development and Personal Relationship with One's managers. Study shows that when employee engagement levels increases, there is a corresponding raise in financial performance as employee engagement is strongly correlated to a number of individual, group, and organisational performance outcomes including recruiting, retention, turnover, individual productivity, growth in operating margins, increased profit margins, customer service, customer loyalty and even revenue growth rates.

Gould-Williams (2003) in his research on the dynamism within non profit organisation management practices, brought together under the banner of "New Non profit Management" gained momentum in the 1980s, and reached extensive appeal with practically all of the government organisations in Australia in the early-to-mid 1990s. The basic difference was that the non profit service has partial financial means to extract higher levels of engagement including non-cash and benefits provided by drivers of engagement have greater resonance. 


\section{PROBLEM STATEMENT}

1. To compare whether there is any difference in the level of employee engagement in non profit and profit organisation.

2. To identify the key drivers affecting employee engagement in profit \& nonprofit organisation.

\section{HYPOTHESIS FRAMED}

H10: There is a significant difference in the level of employee engagement in non profit and profit organisation. H20: There is a significant difference in the key drivers of employee engagement in Non profit and profit organisation.

\section{Sampling size and fieldwork}

\section{METHODOLOGY}

In total 500 questionnaires were send through mails and Google forms. Out of the total responses some questionnaires were incomplete whereas some were discarded as they were outliner. So, a sample size of 480 employees was taken wherein 242 employees were from non profit organisations whereas 238 employees were from profit organisations. Respondents from telecom, banking and insurance from both profit and non profit organisations located in India participated in the survey. Data was collected through both primary and secondary sources for the purpose of measurement of employee engagement drivers. Primary data was collected with the help of self designed structured questionnaires whereas secondary data was collected through published sources such as websites, online journals and magazines.

\section{Questionnaire Designing:}

Self designed questionnaires were utilized in order to achieve the desired objectives:

i. The first part contains the Demographic details of the respondents.

ii. The second part of the survey is the self designed Engagement Survey, containing the twelve drivers of employee engagement is measured on the five point Likert Scale starting from strongly disagree to strongly agree.

A total of 59 questions were selected which were kept under 12 heads as discussed below.

1) Enabling work conditions

2) Enhancement and Learning

3) Motivation

4) Coworker/Team Co ordination

5) Procedural justice

6) Job Fit

7) Compensation and Benefits

8) Supervisor support

9) Commitment

10) Attraction to work

11) Perception about the company

12) Work Life Balance

\section{Framework for Analysis}

To explore whether there is any significant difference between the sample from the two sectors in terms of their levels of engagement at work and difference in the drivers of engagement in the two sectors, the data is subjected to analysis by Independent sample $t$ test or Student's $t$ test. In the study sector (Non profit and profit) is taken as independent variable whereas engagement (drivers of engagement) were taken as dependent variable. The analysis was done in SPSS version 16 in order to anticipate the relationship and impact of drivers of engagement in both the sectors.

\section{a. Reliability Analysis}

Cronbach's Alpha co-efficient was used to find the reliability of the scale developed. The test results showed that the scales were highly reliable meeting the minimum criterion of reliability $(\alpha=0.70)$. If it is between 0.70 to 0.83 then it is moderate and more than 0.83 and closer to 1 , the scale is more and more reliable. The reliability of the Part ' $\mathrm{B}$ 'of the questionnaire on factors of employee engagement scale was $\alpha=$ 0.932 which shows that the scale developed is quite reliable. 
b. Hypothesis Analysis

H10: There is a significant difference in the level of employee engagement in Non profit and profit organisation.

\begin{tabular}{|l|l|l|l|l|l|}
\hline \multicolumn{5}{|c|}{ Table 1. Group Statistics } \\
\hline & Organisation & N & Mean & Std. Deviation & Std. Error Mean \\
\hline E & non profit organisation & 242 & $2.4356 \mathrm{E} 2$ & 21.27723 & 1.36775 \\
$\mathrm{E}$ & profit organisation & 238 & $2.2457 \mathrm{E} 2$ & 29.65671 & 1.92236 \\
\hline
\end{tabular}

TabIe 2. Independent Samples Test

\begin{tabular}{|c|c|c|c|c|c|c|c|c|c|c|}
\hline & & \multicolumn{2}{|c|}{$\begin{array}{l}\text { Levene's Test for } \\
\text { Equality of } \\
\text { Variances }\end{array}$} & \multicolumn{7}{|c|}{ t-test for Equality of Means } \\
\hline & & \multirow[t]{2}{*}{$\mathrm{F}$} & \multirow[t]{2}{*}{ Sig. } & \multirow[t]{2}{*}{$\mathrm{T}$} & \multirow[t]{2}{*}{$\mathrm{df}$} & \multirow[t]{2}{*}{$\begin{array}{l}\text { Sig. (2- } \\
\text { tailed) }\end{array}$} & \multirow[t]{2}{*}{$\begin{array}{l}\text { Mean } \\
\text { Difference }\end{array}$} & \multirow[t]{2}{*}{$\begin{array}{l}\text { Std. Error } \\
\text { Difference }\end{array}$} & \multicolumn{2}{|c|}{$\begin{array}{l}95 \% \text { Confidence Interva } \\
\text { of the Difference }\end{array}$} \\
\hline & & & & & & & & & Lower & Upper \\
\hline \multirow[t]{2}{*}{$\mathrm{EE}$} & $\begin{array}{l}\text { Equal } \\
\text { variances } \\
\text { assumed }\end{array}$ & 27.919 & .000 & 8.069 & 478 & .000 & 18.98642 & 2.35298 & 14.36296 & 23.60988 \\
\hline & $\begin{array}{l}\text { Equal } \\
\text { variances not } \\
\text { assumed }\end{array}$ & & & 8.048 & 429.458 & .000 & 18.98642 & 2.35928 & 14.34925 & 23.62360 \\
\hline
\end{tabular}

- Leven's test shows that as $(\mathrm{p}=0.00, \mathrm{~F}=27.919)$ significance value is less than 0.05 , equal variances cannot be assumed showing that the equal variances cannot be assumed in this case.

- Table 1 shows that in non profit organisation $(\mathrm{N}=242)$ the statistics shows that $\mathrm{M}=2.4356(\mathrm{SD}=21.2772)$ is quite larger than in profit organisation $(\mathrm{N}=238)$ where $\mathrm{M}=2.2457$ ( $\mathrm{SD}=29.656)$ depicting that the nonprofit organisation employees are more engaged than the profit organisation employees. This finding is also supported by Towers Perrin (2003) stating that across industries, engagement is found to be substantially higher in the non-profit sector than other sector. This would appear logical, as in government organisation an employee feel safe and secured due to job security rather than from any prospect of high pay or wealth accumulation

- Independent sample $t$ test results shows that $(p=0.000, T=8.048)$ there is a significant difference in the level of engagement in non profit and profit organisation, thus accepting the hypothesis $\mathbf{H}_{10}$.

H20: There is a significant difference in the key drivers of employee engagement in Non profit and profit organisation.

Table 3. Table of t test

\begin{tabular}{|c|c|c|c|c|c|c|c|c|c|c|}
\hline & & \multicolumn{2}{|c|}{$\begin{array}{l}\text { Levene's Test for } \\
\text { Equality of Variances }\end{array}$} & \multicolumn{7}{|c|}{ t-test for Equality of Means } \\
\hline & & \multirow[t]{2}{*}{$\mathrm{F}$} & \multirow[t]{2}{*}{ Sig. } & \multirow[t]{2}{*}{$\mathrm{t}$} & \multirow[t]{2}{*}{ df } & \multirow[t]{2}{*}{$\begin{array}{l}\text { Sig. (2- } \\
\text { tailed) }\end{array}$} & \multirow[t]{2}{*}{$\begin{array}{l}\text { Mean } \\
\text { Difference }\end{array}$} & \multirow[t]{2}{*}{$\begin{array}{l}\text { Std. Error } \\
\text { Difference }\end{array}$} & \multicolumn{2}{|c|}{$\begin{array}{l}95 \% \text { Confidence Interval } \\
\text { of the Difference }\end{array}$} \\
\hline & & & & & & & & & Lower & Upper \\
\hline \multirow[t]{2}{*}{ EWC } & Equal variances assumed & 17.182 & .000 & -4.623 & 478 & .000 & -1.29346 & .27981 & -1.84328 & -.74364 \\
\hline & Equal variances not assumed & & & -4.627 & 473.348 & .000 & -1.29346 & .27954 & -1.84276 & -.74416 \\
\hline \multirow[t]{2}{*}{ ENL } & Equal variances assumed & 12.999 & .000 & -2.426 & 478 & .016 & -.69168 & .28507 & -1.25183 & -.13153 \\
\hline & Equal variances not assumed & & & -2.422 & 456.875 & .016 & -.69168 & .28555 & -1.25282 & -.13054 \\
\hline \multirow[t]{2}{*}{ MOT } & Equal variances assumed & 2.111 & .147 & -2.597 & 478 & .010 & -.52472 & .20208 & -.92181 & -.12764 \\
\hline & Equal variances not assumed & & & -2.593 & 458.885 & .010 & -.52472 & .20240 & -.92247 & -.12698 \\
\hline \multirow[t]{2}{*}{ TC } & Equal variances assumed & 5.661 & .018 & -1.561 & 478 & .119 & -.30665 & .19648 & -.69273 & .07942 \\
\hline & Equal variances not assumed & & & -1.563 & 470.261 & .119 & -.30665 & .19624 & -.69228 & .07897 \\
\hline \multirow[t]{2}{*}{ PJ } & Equal variances assumed & .587 & .444 & 1.502 & 478 & .134 & .41850 & .27871 & -.12915 & .96615 \\
\hline & Equal variances not assumed & & & 1.503 & 474.745 & .134 & .41850 & .27848 & -.12870 & .96570 \\
\hline \multirow[t]{2}{*}{ JF } & Equal variances assumed & 13.739 & .000 & 3.263 & 478 & .001 & 1.30315 & .39933 & .51849 & 2.08780 \\
\hline & Equal variances not assumed & & & 3.251 & 387.184 & .001 & 1.30315 & .40090 & .51494 & 2.09135 \\
\hline \multirow[t]{2}{*}{$\mathrm{CAB}$} & Equal variances assumed & 9.515 & .002 & 21.347 & 478 & .000 & 8.20283 & .38426 & 7.44778 & 8.95787 \\
\hline & Equal variances not assumed & & & 21.327 & 470.078 & .000 & 8.20283 & .38462 & 7.44703 & 8.95862 \\
\hline \multirow[t]{2}{*}{ SS } & Equal variances assumed & .002 & .961 & 4.271 & 478 & .000 & 1.72564 & .40403 & .93175 & 2.51953 \\
\hline & Equal variances not assumed & & & 4.281 & 447.224 & .000 & 1.72564 & .40309 & .93346 & 2.51783 \\
\hline \multirow[t]{2}{*}{$\mathrm{CM}$} & Equal variances assumed & 2.272 & .132 & .864 & 478 & .388 & .15435 & .17868 & -.19674 & .50544 \\
\hline & Equal variances not assumed & & & .863 & 466.960 & .389 & .15435 & .17888 & -.19716 & .50586 \\
\hline \multirow[t]{2}{*}{ ATW } & Equal variances assumed & 16.250 & .000 & 2.271 & 478 & .024 & .53521 & .23570 & .07208 & .99834 \\
\hline & Equal variances not assumed & & & 2.265 & 434.842 & .024 & .53521 & .23629 & .07081 & 99961 \\
\hline \multirow[t]{2}{*}{ PAC } & Equal variances assumed & 27.151 & .000 & -.093 & 478 & .926 & -.02820 & .30462 & -.62676 & .57036 \\
\hline & Equal variances not assumed & & & -.092 & 424.780 & .927 & -.02820 & .30548 & -.62864 & .57225 \\
\hline \multirow[t]{2}{*}{ WLB } & Equal variances assumed & 31.651 & .000 & 4.647 & 478 & .000 & .68522 & .14747 & .39546 & .97499 \\
\hline & Equal variances not assumed & & & 4.635 & 435.830 & .000 & .68522 & .14783 & .39467 & .97577 \\
\hline
\end{tabular}


There are a variety of drivers of engagement that comes under its umbrella depending upon different types of organisations and the fields of their specialization. In this research twelve factors were considered for study: EWC enabling work conditions, ENL enhancement and learning, TC team coordination, JF job fit, CAB compensation and benefits, ATW attraction towards work, PAC Perception about the company, WLB work life balance, MT motivation, PJ procedural justice, SS supervisor support and CM commitment and the following outcomes appeared:

- Levene's Test for Equality of Variances fro table 3 shows that for enabling work conditions EWC ( $\mathrm{p}=0.000$ , $F=17.182$ ), enhancement and learning $\operatorname{ENL}(\mathrm{p}=0.000, \mathrm{~F}=12.999)$, TC team coordination $(\mathrm{p}=0.018$, $\mathrm{F}=5.661)$, JF job fit $(\mathrm{p}=0.000, \mathrm{~F}=13.739)$, $\mathrm{CAB}$ compensation and benefits $(\mathrm{p}=0.002, \mathrm{~F}=9.515)$, attraction towards work ATW ( $\mathrm{p}=0.000, \mathrm{~F}=16.250)$, PAC Perception about the company $(\mathrm{p}=0.000$, $\mathrm{F}=27.151$ ) and work life balance WLB $(\mathrm{p}=0.000, \mathrm{~F}=31.651)$ equal variances are not assumed as $\mathrm{p}<0.05$ whereas for motivation MT ( $\mathrm{p}=0.147, \mathrm{~F}=2,111)$, procedural justice $\mathrm{PJ}$ ( $\mathrm{p}=0.444, \mathrm{~F}=0.587)$, supervisor support SS $(\mathrm{p}=0.962, \mathrm{~F}=0.002)$ and commitment $\mathrm{CM}(\mathrm{p}=0.132, \mathrm{~F}=2.272)$ equal variances are assumed as $\mathrm{p}>0.05$.

- The most significant factor effecting engagement was found to be Compensation and Benefits with a t statistics 21.327 in the nonprofit organisation. This clearly shows that the employees in non profit organisations are very much satisfied with the benefits provided to them. The nonprofit organisations scored high on the life time security and the pension schemes that are provided in the government organisations thus playing a very static role in engaging the employees to its organisation. Compensation and benefit $\mathrm{CAB}(\mathrm{p}=0.00)$ has a major effect as it is very strongly effecting driver in non profit organisation $\mathrm{M}=30.1818$ ( $\mathrm{SD}=3.9656)$ when compared with profit organisation $\mathrm{M}=21.979(\mathrm{SD}=4.4432)$.

- The second important factor was Work Life balance with $\mathrm{t}$ value 4.635 found higher in non profit organisation indicating that the employees in non profit organisation achieve correct balance between their working life and their family life as they are not overburdened with work. Work Life Balance WLB $(\mathrm{p}=0.00)$ shows that it has a major effect on employee engagement in both the sectors where it has more impact in non profit organisation $\mathrm{M}=12.479$ ( $\mathrm{SD}=1.3579$ ) than in profit organisation $\mathrm{M}=11.794$ $(\mathrm{SD}=1.8406)$.

- The third important variable was Supervisor Support having its t value 4.271, also supported by Schneider et al.(2009) whose study signifies the importance of authentic, transformational and supportive leadership, which plays an important role in nurturing the engagement. Supervisor support SS ( $p=0.00)$ is strongly effecting in non profit organisation $\mathrm{M}=25.074$ ( $\mathrm{SD}=4.9982$ ) in comparison to profit organisation $\mathrm{M}=23.348$ $(\mathrm{SD}=3.7552)$ suggesting that in public undertakings the managers motivate employees to look beyond their own self-interest for the benefit of organisation as well as society. Supervisor support is believed to be especially important for building engagement and to be the root of employee disengagement (Bates, 2004; Frank, Finnegan and Taylor, 2004).

- The fourth vital factor was recognized to be Job Fit with t statistics to be 3.251found higher in non profit organisation. Job fit JF ( $\mathrm{p}=0.001)$ shows that it has significant impact in both the sectors. The statistics shows that it has more effect in non profit organisation $\mathrm{M}=20.099$ ( $\mathrm{SD}=3.1924)$ as compared to profit organisation $\mathrm{M}=19.680$ ( $\mathrm{SD}=5.3192$ ). Good job fit provides the cognitive stimulus for employees to engage in behavior directed toward organizational outcomes (Hoffman Woehr, 2006). In non profit organisations employees experience job fit within their work roles are more likely to perform their jobs with zeal and energy and be engaged in their work, they find their jobs more scheduled, sequenced and full of meaning.

- The fifth important factor found was Attraction to Work with $t$ value 2.265. Attraction towards work ATW $(\mathrm{P}=0.024)$ shows a significant effect in both the sectors. The means shows that in non profit $\mathrm{M}=16.905$ $(\mathrm{SD}=2.1642)$ and in profit $\mathrm{M}=16.369(\mathrm{SD}=2.9464)$ they are almost equally effective. This finding is supported by numerous researches surrounding engagement, which identifies a 'passion for work' as being a key component factor (Truss et al 2006, Brim 2002 and Holbeche and Springett 2003).

- The other important drivers at sixth, seventh and eighth position are Enhancement and learning, Motivation and Enabling work conditions respectively. These three factors show a significant difference in engagement and are more effective in profit organisation as compared to nonprofit organisation. Truss et al (2006) also supported the findings in his study and stated that nonprofit organisation had a more unenthusiastic experience of work, sometimes they have to face more harassment than those in the profit organisation, and were not given enough opportunities to prove their potential. This reinforces the findings of previous studies and put forward challenge distinctively in front of nonprofit organisation managers, and the negative impact that discrimination and harassment have on employees and their levels of engagement (Emmott 2006).

- For Enabling work conditions ENL ( $\mathrm{p}=0.000$ ), this driver of engagement has a significant effect of in non profit and profit organisation. The group statistics shows that it has more impact in profit organisation $\mathrm{M}=21.004$ ( $\mathrm{SD}=2.88090)$ as compared to nonprofit organisation $\mathrm{M}=19.710$ ( $\mathrm{SD}=3.23605)$. In line with the 
findings of (Robinson, 2006) that positive workplace environment will increase confidence and ownership of the organization among employees thereby increasing engagement levels and improve performance. It signifies the availability of resources, high level of freedom to work in private organisations. It can be concluded that the accessibility of resources, autonomy to express ideas and no intrusion in the work increases the level of employee engagement.

- Enhancement and learning ENL ( $\mathrm{p}=0.016)$ showing significant effect in both the sectors. It is slightly greater in profit organisation $\mathrm{M}=21.096(\mathrm{SD}=3.4216)$ than in non profit organisation $\mathrm{M}=20.405$ (SD=2.7976). This is in alignment with Murphy \& Denisi (2008)and Kahn (1990) theories where providing employees with resources such as skills and knowledge to enable them to fully engage in their roles to increase performance, training and learning is considered as an essential factor.

- Motivation ( $\mathrm{p}=0.01$ ) also depicts a significant effect in the two sectors showing it has more effect in profit organisation $\mathrm{M}=16.495 \quad(\mathrm{SD}=2.41435)$ when compared with nonprofit organisation $\mathrm{M}=15.971$ $(\mathrm{SD}=1.99668)$ depicting that profit organisation cares for individual needs and healthy and open discussion are promoted so that the employees are motivated. Saks and Rotman (2006) also supported that recognizing employees and rewarding their efforts is an important step towards engaging them.

- Team co ordination TC $(\mathrm{p}=0.119)$, Procedural justice PJ $(\mathrm{p}=0.134)$, commitment $\mathrm{CM}(\mathrm{p}=0.388)$ and perception about the company PAC $(\mathrm{p}=0.926)$ shows no major effect as the significance value is greater (p>0.05). But several researchers (such as Kahn, 1990; May et al., 2004; Locke and Taylor, 1990) have stated that helpful, trusting and interactive relationship, along with helpful team, transparency and loyalty contributes to supporting and strengthening of employee engagement.

\section{CONCLUSION}

When we hear the term engagement it seems to be a simple concept but as soon as we start moving deep inside the topic, it looks so scattered and typical. Engagement has got so much colours and shades that understanding all is very difficult. According to practitioners engagement is much more than attraction, retention, commitment and quite different from organisational citizenship behaviour (OCB) and corporate social responsibility (CSR). In an organisation turnover percentage can be taken as an indicator of employee engagement. Hence, it needs to be conceived, strategized and driven collectively. Workers engagement depends on a variety of attributes affected by the kind of organisation, prevailing work culture, support from employers and peers, learning and development opportunities, rewards and recognition system etc. and the combination of various predictors is helpful in enhancing the engagement level. Therefore, the researcher has made an attempt to study the variables contributing for employee engagement in profit and non profit service sector in India in the current scenario. In short it can be inferred that compensation and benefits, work life balance, supervisor support, job fit are found to be better in public sector and enhancement and learning, motivation and enabling work conditions are strong in private sector. Attraction to work is equally significant in both the sectors whereas team coordination, commitment, procedural justice and perception about the company show no significant effect in both sectors. Taking correct step by considering these predictors in the field of engagement at the right time can prove to be a boon to the organisations.

\section{Scope For Further Research}

Despite the fact that employee engagement is the most discussed topic still there remains a paucity of critical academic literature on the subject. Although there is a great deal of interest in engagement, there is also a good deal of confusion. Presently, there is no consistency in definition, with engagement having been operationalized and measured in many disparate ways. In this study the researcher has considered limited drivers of engagement, other unobserved exogenous variables like socio cultural predictors, biographic predictors etc can also be considered. In the present study only service sector consisting telecom, banking and insurance companies from selected cities are considered. Other companies in service sector as well as other than service se tor companies can also be taken for further research having more sample size. The study of the extent of relationship between engagement and its predictors would be very beneficial for the success of the organisations so more and more research should be done in this context.

\section{BIBLIOGRAPHY}

[1]. Akwasi Opoku-Dakwa. (2010). Perceived impacts and employee engagement in corporate volunteering: An interactionist perspective. Rutgers Business School www.ivey.uwo.ca/cmsmedia/439298/

[2]. Baumruk, R. (2004). The missing link: the role of employee engagement in business successes. Workspan, Vol. 47, pp. 48-52.

[3]. Bhargavi V.R. (2015). Study on Employee Engagement and its impact on organizational effectiveness in select global companies in Bangalore city opportunities and empowerment. Mother Teresa Women's University, 
[4]. Kodaikanal.

[5]. Dr.Bhavana Adhikari, Ms.Ridhi Arora. (2011). Dispositional Factors as Determinant of Employee Engagement in IT Sector: A Study in NCR Delhi. http://works.bepress.com/ridhi_arora/1

[6]. Ferguson, A. (2007). "Employee engagement: does it exist, and if so, how does it relate to performance, other constructs and individual differences?" [online] Available at: http://www.lifethatworks.com/Employee-Engagement.prn.pdf.

[7]. Frank, F.D., Finnegan, R.P., Taylor, C.R. (2004). "The race for talent: retaining and engaging workers in the 21st century", Human Resource Planning, Vol. 27, Issue. 3, pp.12-25.

[8]. Truss, C., Soane, E., Edwards, C., Wisdom, K., Croll, A. and Burnett, J. (2006) Working Life:Employee Attitudes and Engagement 2006. London, CIPD.

[9]. Kahn, W.A. (1990). "Psychological conditions of personal engagement and disengagement at work". Academy of Management Journal, Vol. 33, Issue.4, pp.692-724.

[10]. Macey, W.H. and Schneider, B. (2008). The meaning of employee engagement. Industrial and Organizational Psychology, Vol. 1, pp. 3-30.

[11]. May (2007). Employee Engagement in the Non profit organisation: A review of literature. Scottish Executive Social Research

[12]. Michael B. Shuck. (2010). Employee Engagement: An Examination of Antecedent and Outcome Variables. Florida International University.

[13]. Peeters, M., Wattez, C., Demerouti, E., and de Regt, W. (2009). Work-family culture, work-family interference and well-being at work: is it possible to distinguish between a positive and a negative process? Career Development

[14]. International, Vol. 14, Issue 7, pp. 700-713.

[15]. Robinson, D., Perryman, S. and Hayday, S. (2004). The Drivers of Employment Engagement. Brighton, Institute for Employment Studies, Brighton.

[16]. Sandeep Kular, Mark Gatenby, Chris Rees, Emma Soane, Katie Truss. (2008). Employee Engagement: A Literature Review. Kingston Business School.

[17]. Saks, A.M. (2006). "Antecedents and consequences of employee engagement". Journal of Managerial Psychology, Vol. 21, Issue. 6, pp. 600-619

[18]. Somasundaram Subramanian, Kruthika J. (2012).Comparison between Public and Private Sector Executives on Key Psychological Aspects. Journal of Organisation \& Human Behaviour, Volume 1 Issue 1.

[19]. S. Gokula Krishnan. (2014). Employee Engagement and its impact on Intention to Quit. Master's Thesis, Karunya Institute of Technology and Sciences, Coimbatore.

[20]. Shweta Vaibhav Vohra. (2013). "A study of Employee Engagement Practices

[21]. in select IT companies in and around Pune". Thesis, University of Pune.

[22]. Md. Hassan Jafri. (2013). HRM Practices as Predictors of Employee Engagement: An Empirical Investigation. Anvesha, Vol. 6 No. 4.

[23]. Sugandh Rawal. (2014). Employee Engagement and Organizational Commitment in Insurance Industry: A Comparative Study of Private and public Companies. Institute of Management Studies and Research, Maharshi Dayanand University, Rohtak.

[24]. T. Arunmozhi Manonmaniam. (2013). A Study on Employee Engagement and Involvement Practices in ICICI Bank Ltd., Chennai. Sundaranar University, Tirunelveli, Tamil Nadu. 